\title{
HIGH VOLTAGE MEASUREMENTS ON A PROTOTYPE PFN FOR THE LHC INJECTION KICKERS
}

\author{
M.J. Barnes, G.D. Wait ${ }^{\star}$, TRIUMF. Vancouver, B.C., Canada \\ E. Carlier, L. Ducimetière, G.H. Schröder, E.B. Vossenberg, CERN, Geneva, Switzerland
}

\section{Abstract}

Two LHC injection kicker magnet systems must produce a kick of 1.3 T.m each with a flattop duration of $4.25 \mu \mathrm{s}$ or $6.5 \mu \mathrm{s}$, a rise time of $900 \mathrm{~ns}$, and a fall time of $3 \mu \mathrm{s}$. The ripple in the field must be less than $\pm 0.5 \%$. The electrical circuit of the complete system has been simulated with PSpice[3]. The model includes a $66 \mathrm{kV}$ resonant charging power supply (RCPS), a $5 \Omega$ pulse forming network (PFN), a terminated $5 \Omega$ kicker magnet, and all known parasitic quantities. Component selection for the PFN was made on the basis of models in which a theoretical field ripple of less than $\pm 0.1 \%$ was attained. A prototype $66 \mathrm{kV}$ RCPS[1,6] was built at TRIUMF and shipped to CERN. A prototype $5 \Omega$ system including a PFN[2], thyratron switches, and terminating resistors, was built at CERN. The system (without a kicker magnet) was assembled as designed without trimming of any PFN component values. The PFN was charged to $60 \mathrm{kV}$ via the RCPS operating at $0.1 \mathrm{~Hz}$. The thyratron timing was adjusted to provide a $30 \mathrm{kV}, 5.5 \mu$ s duration pulse on a $5 \Omega$ terminating resistor. Measurement data is presented for the prototype PFN, connected to resistive terminators. A procedure has been developed for compensating the probe and oscilloscope amplifier calibration errors. The top of the $30 \mathrm{kV}$ pulse is flat to $\pm 0.3 \%$ after an initial oscillation of $600 \mathrm{~ns}$ total duration. The post-pulse period is flat to within $\pm 0.1 \%$ after approximately $600 \mathrm{~ns}$ from the bottom of the falling edge of the pulse. A calculation was performed in which a measured $27.5 \mathrm{kV}$ pulse with a $5.5 \mu$ s flattop was fed into a PSpice model of a kicker magnet with a $690 \mathrm{~ns}$ delay length. The resultant predicted kick rise time, from $0.2 \%$ to $99.8 \%$, is $834 \mathrm{~ns}$ and the fall time $2.94 \mu \mathrm{s}$, for a field pulse with a flattop of $4.69 \mu$ s and a ripple of less than $\pm 0.2 \%$.

\section{INTRODUCTION}

The European Laboratory for Particle Physics (CERN) is designing a Large Hadron Collider (LHC) to be installed in an existing $27 \mathrm{~km}$ circumference tunnel. The LHC will be equipped with Injection Kicker Systems, devices for providing a fast deflection of the incoming particle beams onto the accelerator's circular trajectory. Two pulsed systems, of 4 magnets and 4 PFN's each, are required for injection. The injection sequence, during normal operation, consists of 12 pulses with a period of $16.8 \mathrm{~s}$.

Email: wait@triumf.ca
Fig. 1 shows a schematic of the prototype LHC injection kicker system. The $5 \Omega$ PFN consists of two lumped element delay lines, each of $10 \Omega$ impedance, connected in parallel. There are two thyratron switches connected to the PFN, referred to as a main switch (MS) and a dump switch (DS). Each $10 \Omega$ PFN consists of 23 seven-turn cells, a five-turn cell at the DS end, and a nine-turn cell at the MS end. A cell consists of a series inductor, a damping resistor connected in parallel, and a capacitor connected to ground. Each capacitor is mounted in a coaxial housing to minimise parasitic inductance. The prototype PFN capacitors are selected in pairs from a batch of capacitors with $\pm 5 \%$ tolerance to provide an effective tolerance of $\pm 0.5 \%$ for each pair [2]. Each capacitor per pair is mounted in the same corresponding cell of the parallel lumped element delay lines. The capacitance values are graded linearly from the MS to the DS with a gradient of $+0.09 \%$ per cell [7]. Two, $3.85 \mathrm{~m}$ long, 175 turn coils are mounted on rigid fibreglass coil formers: The total inductance variation per pair of 7 turn coils over the length of the coils is $3 \%$.

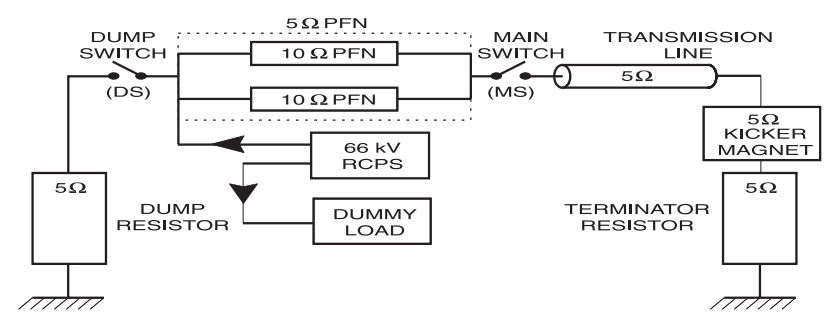

Figure 1: Prototype LHC injection kicker system.

Fig. 1. of reference [6] shows a simplified schematic of the prototype RCPS. The prototype RCPS consists of a $2.6 \mathrm{mF}$ storage capacitor bank $\left(\mathrm{C}_{\text {storage }}\right)$ charged up to $2.8 \mathrm{kV}$. A GTO [5] was used to switch the energy on the storage capacitor bank onto the primary of a 1:23 step-up transformer of low leakage inductance. The output of the secondary is connected to each of two loads through a cable, a $70 \Omega$ resistor and a diode stack. Each $5 \Omega$ PFN can be considered as a $0.96 \mu \mathrm{F}$ capacitor during the charge cycle, which will later be discharged through a kicker magnet using thyratron switches. The MS thyratron is a CX2003[4] and the DS thyratron is a CX1171A[4]. Since there is only one prototype PFN, the test set-up included a dummy load (a $0.96 \mu \mathrm{F}$ capacitor with a parallel $500 \mathrm{k} \Omega$ discharge resistor) connected in place of a second PFN. Thus the RCPS was properly loaded. The DS thyratron connects one end of the prototype PFN, via 10 parallel $50 \Omega$ coaxial cables to the $5 \Omega$ prototype dump 
resistor. The MS connects the other end of the PFN via 10 parallel $50 \Omega$ cables, to a kicker magnet (not installed for these tests) terminated with a $5 \Omega$ MS resistor.

\section{MEASUREMENTS}

The prototype PFN was charged to various voltages up to $60 \mathrm{kV}$ and the timing of the thyratron trigger pulses were varied. The stability and the pulse to pulse reproducibility of the PFN voltage, the ripple of the flattop of the pulse and the ripple in the post pulse period were measured with high precision. A calibration procedure was developed to provide measurements on the ripple of a $30 \mathrm{kV}$ pulse to a precision of $\pm 0.1 \%$ [12].

\subsection{Stability}

The overall stability of the RCPS and PFN was determined by measuring the magnitude of the flattop voltage on the MS terminator voltage divider (VD), on successive pulses. A TDS744A oscilloscope[8] was used to determine the average value of the flattop of the MS VD voltage over a $4 \mu$ s time window, permitting 5 figures of accuracy to be displayed on the oscilloscope. Although the absolute value of voltage is not known to such a high precision, the relative value is mainly of interest. The value of the average voltage was noted for several consecutive pulses, under a variety of conditions, such as a cold start-up, and also after operation for several hours. The maximum excursion of the MS VD voltage for 20 consecutive pulses, with the PFN pre-charged to $60 \mathrm{kV}$, was $\pm 0.035 \%$, compared with a goal of $\pm 0.2 \%$.

\subsection{Probe Calibration}

A $1 \mathrm{kV}$ FET, precision, calibration pulse generator[9] with a transition time of $30 \mathrm{~ns}$ (5\% to 95\%) has been designed and built at TRIUMF. This pulse generator was used to obtain calibration data for a freon filled P6015[8] high voltage probe connected to a TDS744A oscilloscope. The calibration of a 6015A (freon free) probe was found to be sensitive to slight changes in parasitic capacitance to ground of the surroundings. A PSpice model of the precision pulser shows that the output waveform is flat to within $\pm 0.1 \%, 100 \mathrm{~ns}$ after the start of the pulse. The required compensation can not be achieved using the available adjustments in the P6015 probe compensation box. Thus a procedure was developed to provide a relative precision of $\pm 0.1 \%$ for a 6015 probe as follows:

- Use a FET based pulse generator to generate a "known" waveform. Compensate the probe and store this reference waveform digitally. The compensation at this stage is only approximate.

- Comparison of the reference and "known" waveforms gives the calibration curve (for a given waveform shape), as a function of time, for the probe and oscilloscope amplifier (for a given gain).
The calibration depends on the oscilloscope amplifier gain and on the waveform shape. Thus the calibration pulse must have approximately the same duration, rise time and fall time as the pulse to be measured, and the oscilloscope settings must be the same for the calibration data collection as for the PFN pulse data collection [12]. The $30 \mathrm{kV}$ MS terminator pulse was measured across one of ten series resistor disks that make up the MS terminating resistor. Thus the $\mathrm{P} 6015$ probe was used to measure a $3 \mathrm{kV}$ pulse, and was calibrated with a $600 \mathrm{~V}$ pulse with the same amplifier gain settings on the TDS744A oscilloscope.

\subsection{Flat-top}

Fig. 2 shows a measured $29 \mathrm{kV}$ pulse, after compensation for the 6015 probe and the oscilloscope amplifier, with the DS not turned on. The waveform has been corrected to account for the calibration. The top of the measured voltage pulse is flat to within $\pm 0.3 \% 600$ ns after the end of a rise time of approximately $60 \mathrm{~ns}$, without any adjustments of the PFN.

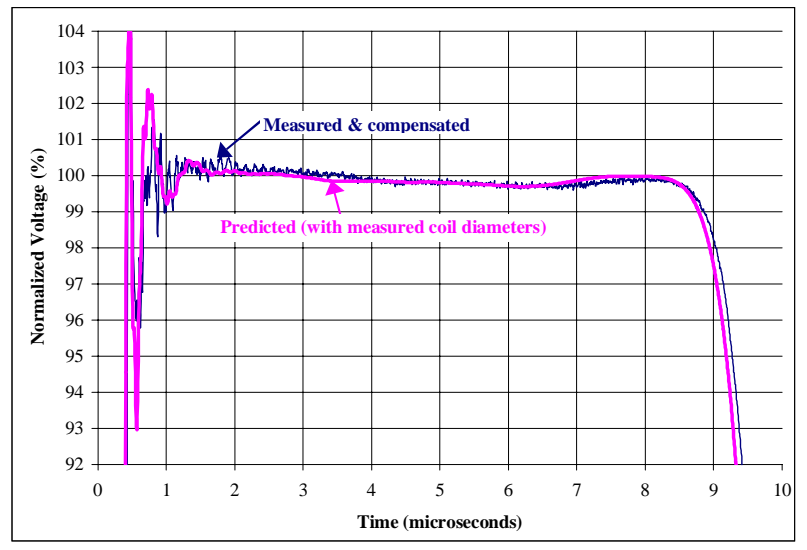

Figure 2: Measured and predicted flattop portion of PFN voltage pulse each normalised to $100 \%$.

Measurements on a 7 turn section of the PFN coil showed that the copper tube from which the coil is made was no longer round. The outside diameter of the tube on the length of the helix was between $0.2 \mathrm{~mm}$ and $0.3 \mathrm{~mm}$ larger than the nominal $8 \mathrm{~mm}$. Since the coil former has grooves to fit the $8 \mathrm{~mm}$ circular cross section of copper tubing, the coil diameter is slightly too large. Detailed measurements of the outside diameter of the PFN coils at each cell, showed that the average mean coil diameter is $1.4 \%$ greater than the designed mean diameter, giving rise to an average increase in inductance of $2.8 \%$. The average diameter of the cells near the centre of the PFN is $1.5 \%$ and $0.8 \%$ greater than at the MS and DS ends, respectively. The prediction in Fig. 2 is a PSpice calculation with measured coil diameters used to scale the PFN cell inductance. A PSpice prediction for an ideal PFN coil (constant diameter) gives a waveform that is flat from an elapsed time of $1.2 \mu \mathrm{s}$ through to $8 \mu \mathrm{s}$. The variation in 
the coil diameter explains the small dip in the voltage waveform at approximately $6 \mu \mathrm{s}$ in Fig. 2.

Analysis of measurements made at low voltage, (up to $50 \mathrm{~V}$ ) indicate that the inductance of each cell of the PFN is approximately $4 \%$ greater than predicted for an ideal (constant radius) coil. Thus there is still an unexplained anomaly of $1.2 \%$ error in the total PFN inductance. The relative difference between the predicted flattop ripple and the actual measured waveform is $\pm 0.2 \%$, from $1400 \mathrm{~ns}$ after the start of the flattop of the pulse.

The field strength was calculated from a measured $27.5 \mathrm{kV}$ pulse with a $5.5 \mu \mathrm{s}$ flattop, fed to the model of the kicker magnet with a $690 \mathrm{~ns}$ delay length. The resultant predicted kick rise time from $0.2 \%$ to $99.8 \%$, is $834 \mathrm{~ns}$ and the fall time is $2.94 \mu \mathrm{s}$, for a field pulse with a flattop of $4.69 \mu$ s and a ripple of less than $\pm 0.2 \%$.

\subsection{Post Pulse}

It was thought that the 3 stage thyratrons would block reverse voltages up to a few $\mathrm{kV}$ and would conduct at higher reverse voltages[10]. In order to confirm that small reverse voltages are blocked, the post pulse period of a waveform was measured at the MS terminator for two different values of DS terminating resistor. The results are shown in Figure 3 for a $27.5 \mathrm{kV}$ pulse.

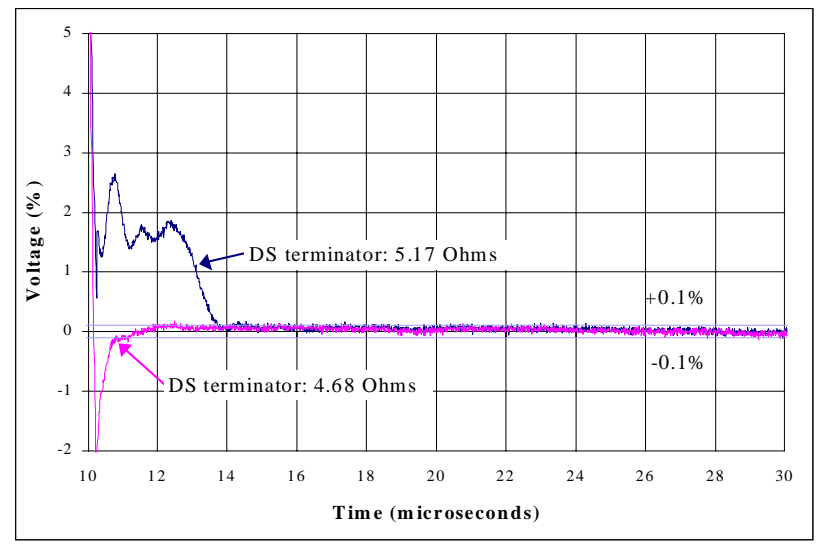

Figure 3. Post pulse voltage for a positive and a negative reflected pulse from the DS terminator.

Assuming that the PFN impedance is exactly $5 \Omega$ at the DS end, then with a DS resistor of $5.17 \Omega$, the reflection coefficient is $+1.7 \%$ and there is a small positive pulse reflected back to the MS terminator which shows up in as a positive distortion during the post pulse period (Fig. 3). However with a DS resistor of $4.68 \Omega$, the reflection coefficient is $-3.3 \%$ and there is a negative pulse reflected back which would show up as a negative pulse, with a magnitude of approximately $-3.3 \%$. However there is only a small and short negative pulse (Fig. 3), which confirms that the MS thyratron (CX2003) blocked a reverse voltage of $6.6 \%$ (ie: $1.8 \mathrm{kV}$ due to pulse doubling). This means that the precision of the DS terminator does not have to be very high (e.g. $5 \Omega+0 \%-6 \%$ ). The small negative pulse (Fig. 3) is thought to be due to the cleanup current from the MS thyratron. There is also a probe calibration error, since the calibration pulser fall time is $30 \mathrm{~ns}$ and the fall time of the measured pulse is approximately $1 \mu \mathrm{s}$. A new calibration pulser has been designed to permit calibration with pulses of representative fall time [11].

\section{CONCLUSION}

The top of the $29 \mathrm{kV}$ pulse is flat within $\pm 0.3 \%$ after $600 \mathrm{~ns}$ from the start of the flattop of the pulse. The postpulse period is flat to within $\pm 0.1 \%$ after a period of approximately $600 \mathrm{~ns}$ from the bottom of the falling edge of the pulse, providing the resistance of the DS terminator is slightly less than $5 \Omega$. The PSpice calculations of the system are accurate to the $0.2 \%$ level and thus the theoretical model can be applied with confidence to evaluate future PFNs and RCPSs. A kicker magnet is being fabricated, and measurements will be carried out to confirm that the field pulse can meet the stringent requirements. The prototype PFN and RCPS have met the design specifications so TRIUMF can now proceed to fabricate 9 PFNs and 5 RCPSs for installation into the LHC.

\section{REFERENCES}

[1] M.J. Barnes, G.D. Wait, E.Carlier, L. Ducimetière, G.H. Schröder, E.B. Vossenberg, "Measurements on a Fast $66 \mathrm{kV}$ Resonant Charging Power Supply", Proc. of EPAC 1998, Stockholm Sweden, June 1998, pp2278-2280.

[2] M.J. Barnes, G.D. Wait, L. Ducimetière, G.H. Schröder, E.B. Vossenberg, "Kick Sensitivity Analysis for the LHC Inflectors", Proc. 23rd Power Modulator Symposium, California, June 1998, pp96-99.

[3] OrCAD, 9300 SW Nimbus Ave., Beaverton, OR 97008 USA.

[4] EEV Limited, Waterhouse Lane, Chelmsford, Essex CM1 2QU, United Kingdom.

[5] Westcode Semiconductors, "Gate Turn-Off Thyristor (Symmetrical blocking type.) Types WG15026Rxx to WG15045Rxx", August 1996, Rat.Rep.96G9, Issue-3.

[6] M.J. Barnes, G.D. Wait, L. Ducimetière, E. Carlier, U. Jansson, G.H. Schröder, E.B. Vossenberg, "Design and Optimisation of a $66 \mathrm{kV}$ Resonant Charging Power Supply for the LHC Inflectors", Proc. of $11^{\text {th }}$ IEEE Pulse Power Conference, Baltimore, June1997, pp1309-1314.

[7] M.J. Barnes, G.D. Wait, L. Ducimetière, U. Jansson, G.H. Schröder, E.B. Vossenberg, "Kick Stability Analysis of the LHC Inflectors", $5^{\text {th }}$ EPAC, Barcelona, June 10-14, 1996, pp2591-2593

[8] Tektronix Inc., Wilsonville, Oregon 97070-1000, USA.

[9] M.J. Barnes, G.D. Wait, L. Ducimetière, G.H. Schröder, E.B. Vossenberg, "Construction and 60kV Tests of the Prototype Pulser for the LHC Injection Kicker System", to be presented at $12^{\text {th }}$ IEEE Int. Pulsed Power Conference, California, June 1999.

[10] Private communication with Ron Sheldrake, EEV Limited, Waterhouse Lane, Chelmsford, Essex CM1 2QU, United Kingdom

[11] Michael Barnes \& Gary Wait, "Design of a FET Based Push-Pull Pulse Generator for Probe Calibration", Design note TRI-DN-99-02, January 29, 1999.

[12] Michael Barnes \& Gary Wait, "Obtaining and Utilising Calibration Data for High Precision Voltage Pulse Measurements", Design note TRI-DN-98-15, October 2, 1998. 